\title{
The Role of Higher Vocational Education in National Innovation Chain
}

\author{
Li-ping WANG
}

Nanjing Vocational Institute of Technology, Institute for Quality Education, Nanjing, Jiangsu, China

Keywords: Innovation chain, Innovation output, Conversion rate, Soft innovation, Technological post-market.

\begin{abstract}
What position and what to do in the national innovation chain for higher vocational education, is the question we are studying. We investigated the division of knowledge production and the types of talents in different types of universities to establish the orientation of higher vocational education. Then, connecting with the definition of innovation in the classic literature of the United States and Europe, we find the new connotation, new requirements and new forms of innovation in the industry 4.0 era and new consumption age, to respond to "what can do" in the innovation chain for higher vocational education. We believe that higher vocational education should regard technology transformation, soft innovation, new ideas of technology and business method innovation as the dimension of innovation, and focus on technological innovation and transformation in the field of technological post-market, middle-low and middle-high technological industries.
\end{abstract}

\section{Introduction}

The idea of "innovation chain" was put forward by Joseph Alois Schumpeter, a famous American economist, in 1912.He believed that innovation is not a purely scientific and technological category, but also an economic category. Only introducing the invented technology into the production of the enterprise, can form a new production capacity. This research shows that the core technology is only the starting point of innovation activities and there is still a great distance from it to a marketable, commercialized and sensible commodity or economic benefit. The whole innovation activity is a process continuing to value and evolving in many intermediate links that revolves around the core technology. It is a complete chain of product innovation based on the division of labor and difference and the vertical "sci-tech innovation system based on technology matching". It reveals the flow, transformation, value-added and marketization of knowledge and technology in the field between science-technology and economy, and reflects the value transfer relationship connecting and cooperating each other between the different creative subjects in the whole innovation process.

\section{Classification of Knowledge and the Position of HVE in the Innovation Chain}

Knowledge can be divided into scientific knowledge, technical knowledge and application knowledge. The different types of colleges on innovation chain needs further cooperation and division of labor on knowledge production in the process of knowledge extension and expansion, which is the need of disparate development of higher education. The research university funded by the government should not be excessive erosion and give up their humanistic and academic tradition. It is responsible for scientific knowledge production mainly, cultivates academic scientists and engineers and pays attention to develop the students' ability of original innovation of technology and tackling key problems of human fatal science and grand engineering. In the sci-tech innovation chain, it is in the upstream stage of accumulation and production, focusing on the discovery of basic theory, basic data and core technology. Application-oriented universities should cultivate advanced and applied talents of "research and development", "integrated innovation" and "engineering technology application", also product technical knowledge mainly. In the chain of sci-tech innovation, it is in the middle stage of integrated innovation, product development and project 
design, focusing on the transformation from the basic theory of high and new technology to the scientific and technological plan and the product plan. Unlike the former, HVE should cultivate innovative talents that can apply technical skills in production, focusing on the creative implementation of production programs, the ability of manufacture, installation, debug and other soft applications such as marketing and management, mainly producing applied knowledge. In the chain of sci-tech innovation, it is in the downstream phase of materialization of core technology and implementation of the scientific and technological scheme, focusing on the process of production, operation and management.

Worldwide, "research intensive universities in all industrial developed countries are actively seeking opportunities to commercialize the creative ideas of their own professors." Under the threshold of the association of education and technology, HVE is shouldering the realization of materialization of core technology and its mission of connecting with market in the innovation chain. Therefore, the theory and data of technology go from abstract to concrete, from laboratory to real economy and social life, to realize its economic benefit, social benefit and ultimately contribute to human development.

\section{Reconsidering the Scope of "Innovation”}

People take the sci-tech innovation regard as scientific invention. The equivalence is narrow so much. When we discuss the position of HVE in the innovation chain, we must also take an open view and absorb the new ideas and methods about "innovation" at home and abroad, and consider all aspects of "what is innovation".

\section{Innovation Should Include the Technological Post-market}

As a practice activity of human beings, besides the original innovation such as technology, the type of innovation is very extensive. The Oslo Manual (2011, third), jointly developed by the Organization of Economic Cooperation and Development (OECD) and the European Union Statistics Agency (Eurostat), has removed the word "technology" in the definition of "innovation", and take "innovation" recognized as "a product (goods or services), a craftwork, a new marketing approach to the realization of a new or significant improvement, or a new organization on business strategy, workplace or external relationship, etc." Here, it obviously weakens the significance of sci-tech innovation, and regards sci-tech innovation as a basic and source innovation. Instead, it pays more attention to technological improvement, product development and consumer services around technology, that is, the post technology market.

\section{The Realization of Innovation is More Dependent on the Transformation and Reorganization of Technology}

According to Joseph Alois Schumpeter idea "innovation refers to any creative activity that is beneficial to diversity and profits", any new and high technology must pay attention to practical application and transform itself into a certain market profit. The results of the European PILOT project show that the innovation ability of (especially the low - tech industry) is mainly transformative capability and configurational capability. The former refers to continuously transforming the externally collating knowledge that can be utilized into its own unique and applicable knowledge. The latter refers to the ability to reassemble different types of dispersed knowledge, dispersed participants, and the functions, characteristics and methods of products.

\section{Soft Innovation is also an Important Innovation}

Academician Wang Zhongtuo, the Chinese Academy of engineering, believes that we should raise soft technology and soft innovation to the strategic height and attach to the sci-tech innovation plan. ${ }^{[2]}$ In the development of industry, this kind of innovation is closely linked to the service industry. 1980s Japanese Soft series of technology concept, 2008 United Nations long report "creative economy", and the "soft innovation" report of the United Kingdom (NESTA) in 2009, 
reform an international consensus of "innovation" that is becoming more and more extend from hard innovations, for example technical innovation and function innovation, and other soft innovation such as service, organization, management and aesthetics.

\section{The Low-tech Industry and the Middle-high Technology Industry Need More Innovation}

OECD divides the industry into four technical levels, such as high, middle-high, middle-low and low, with R\&D density (the percentage of R\&D input) as the index. In 2002, the European "low technology policy and innovation" (PILOT) project through a large number of case studies, found that "economic restructuring is not entirely from emerging industries, but to a large extent the continuous transformation of existing industries." Among them, the middle-low technology industries have solved most of the labor and employment of various countries. It is also the main motive force of the economic development of all countries. It has an irreplaceable role in the economic development. Different from the radical innovation of the high-tech industry focusing on R\&D investment, the middle-low technology industries mainly make a gradual process innovation through the recombination or transformation of all kinds of available resources. The middle-high technology industry focuses on product quality, production efficiency and product design to enhance the accumulation of key technology and sci-tech innovation.

\section{Business Method Innovation is an Important Innovation}

Since the invention of counterfeit banknote issued by Jacob Perkins (USA) in May 19, 1799, the business method patent has been more than 200 years old. At present, the US, Japan and Europe have formally recognized it and carried out a "enclosure movement" in the field of business method patents. American business method patents are mainly covered by 705 categories of patent classification, which mainly include the follow corresponding methods producing business operations, administration, enterprise management or financial data reports, determining data processing and operations, the cost of goods and services. China does not yet recognize the patentability of pure commercial methods, but the new edition of The Patent Review Guide, which began in April 1, 2017, has extended the scope of patent protection to commercial modes and constituent methods that contain technical features. Business method innovation focuses on the organizational change of business operation. It is a kind of intellectual innovation based on the dual basis of technology and market. It has the possibility of hatching many new types of industry with huge commercial value.

From the discussion and practice of innovation at home and abroad, the scope of "innovation" is constantly extending. Original innovation and basic research have only become part of the whole innovation chain, and its industrial application and transformation become more and more important of innovation. As Homer-Dison's new definition on ingenuity: "it is a concept that can be used to solve practical, technical and social problems...Although it is not very novel but very useful "This type of "useful" innovation is also more abundant, and the mode innovation that does not rely on computer technology and experimental data should also be highly valued.

\section{Key Fields of Sci-tech Innovation in Higher Vocational Education}

In the field of sci-tech innovation, HVE should utilize its own market sensitivity to directly face consumers, serve social life, concentrate on the industrialization, Commercialization and marketing of core technology, and implement the core technology.

\section{Promoting the Innovation of Practical Products}

The advantages of HVE in the innovation chain are the deep understanding of market demand, capacity and dynamics, the profound cognition of consumer consumption habits, consumer psychology, life needs, and the accurate grasp of the business model and the way of economic organization, accurately matching the technical resources with the actual needs. The practical product has realized the close combination of high technology and consumption demand, is the real 
product of the original innovation, and the closest media to the target group. From the recent three years of high-tech achievements, it's advantage lies mainly on the utility model patents and the appearance design patents. It should continue to concentrate on the research and elaborate development of practical new products, in order to improve the production efficiency and improve the people's living standard. In the direction of intelligence, green, convenience, health and safety, it should research new products utilizing the latest new technology, known technology, effective patent to improve equipment function, dedicate to "user friendliness", and meet the needs of social production and life.

\section{Promote the Improvement and Transformation of Productive Equipment}

Theoretically, product functions can be pushed forward indefinitely. The main function is more stable, accurate and compatible, and has better maneuverability and adaptability. At the same time, it can also emerge variable and fine derivative functions facing to different environments, different conditions, different enterprises or consumers, and comply with the diversified and special requirements of consumers and productive enterprises. In order to improve productive efficiency and reduce productive energy consumption, higher vocational talents should uphold the attitude of diligence and excellence, and apply advanced technology to the technical specifications, functional positioning, production process, formula ratio, line transformation, material use, transportation, system components, testing methods of the existing production equipment. Look the design and other aspects. With safety performance and cost saving as the driving force for innovation, the innovation should be responsible for the problems in production practice and the needs of people's lives and find a series of solutions. It is necessary for students to look forward to the trend of industrial development in the macroscopic view, to understand the potential functional requirements of the customers, and to improve the existing equipment and technology more carefully on the basis of this, on the basis of this, to advance a step on the road of sci-tech innovation. Higher vocational talents can combine all the existing technical items organically, effectively integrate various useful elements to optimize and upgrade the product into an internal harmonious running state, and finally integrate a new product or new process production to achieve a higher level of technological integration innovation.

\section{Promote the New Meanings of Creativity}

Technological meanings is a weakness in the development of Chinese innovation cause, and has not yet entered the talent training program of HVE. According to the 2016 WIPO global innovation index report, in 128 countries and economies, Chinese creative meanings output is relatively backward, 2010-2016 years on average ranked fifty-eighth in the world, ninety-second in 2016, thirty-eighth in creative products and services, and there is still a big gap with the high income economy. The higher vocational students possess a sound knowledge structure, active thinking, a solid foundation of theoretical knowledge of high and new technology, a keen insight into the market, the consumer and the development of the industry, a full sense of the aesthetic psychology and cultural mentality of the time. They can be the main force of creative meanings. HVE should integrate scientific and technological creative meanings into the training system of their innovation ability, guide them to blend technology with economy and culture perfectly, strengthen the emotional expression and aesthetic presentation of products. They should be Inspired to boldly break the product performance, application, procedure, color, modeling and packaging to make different functions, and learn to develop new products by combination and migration so as to meet the increasing demand of the Chinese people for creative products.For the first time, China proposed that "colleges must build a batch of industrial creative gardens, incubate and foster a number of key enterprises of technology and culture", which provides a direction for the sci-tech innovation of HVE.

\section{Promote Soft Innovation}

In addition to focusing on product innovation and sci-tech innovation, The Oslo Handbook (2011, 
Third Edition) also put forward the concept of marketing innovation and organizational innovation. Because of the intimacy of technology application and the intimacy of the market in higher vocational education, we should cultivate students' soft innovation ability. (1) to cultivate the students' organizational innovation ability. We should guide students to understand the relationship between economic and political, cultural and other social systems, understand the internal and external environment of enterprise development, grasp the management methods, mechanisms, processes, systems and policies of enterprise operation, and have the early knowledge base of organizational innovation. Higher vocational students should be able to put forward the innovative development strategy of enterprises according to the macro and micro environment, put forward innovative organizational methods for the workplace, departments and personnel, and can innovate the relationship between enterprises and society, products and markets, enterprises and customers, and promote the allocation of resources and the rational distribution of elements. Tap the potential of human resources, improve the output of manpower, the quality of work and the efficiency of enterprise operation. (2) to cultivate the students' ability of marketing innovation. Higher vocational education should cultivate students' keen market perception ability, have certain judgment ability for market demand, dynamic and future trend, have accurate positioning for the target consumer group and application field of the product, and have an innovative development for the distribution channel, distribution method, promotion formula and pricing strategy of the product. There is an innovative idea for the opening of the new market, the promotion of new products and the expansion of new channels, thus improving the sales and market share of the products and promoting the further marketization of sci-tech innovation. (3) to cultivate the students' financial innovation ability. Higher vocational education should cultivate the cost concept of students, reduce the cost of production from the aspects of sci-tech innovation, product material updating and production process innovation, and reduce the cost of circulation and innovation cost management. In the case of a large increase in human cost, we should learn to scientifically set up the proportion of all kinds of talents, innovate the development ability and incentive measures of human resources, and reduce the cost of human resources. In terms of enterprise management mode, we should reduce management level, innovate the flat organizational structure of enterprises, reduce the loss of internal benefits, and enhance the operational efficiency of enterprises. (4) innovation of business model. Higher vocational students have strong entrepreneurial intention, active thinking, easy to accept new things, sensitive to consumer trends and market changes, and can break through the conventional mode in the era of digital economy and develop new business operation schemes. Higher vocational colleges should guide students to investigate the shortcomings of the current commercial ecology or the development of a certain industry, encourage students to change or improve the current business ecology as their own responsibilities, and innovate the scheduling of various commercial resources and elements, and carry out the customer relationship, the way of profit, the flow of resources, the internal structure, the supply chain and so on in this industry. Breakthrough development.

\section{To Promote Technology Service}

Some opinions support to speed up the development of technological service industry, such as China National Scientific and sci-tech innovation Plan (2006-2020) proposed that the technology service industry should be vigorously developed. By 2020, the industrial scale reached 8 trillion yuan, and the proportion of the value added to the gross domestic product was $20 \%$. The number of intellectual property professionals has reached more than 50 million people, including more than 3 people in intellectual property administration and law enforcement personnel, more than 30 intellectual property rights personnel and more than 15 people in the intellectual property service industry, of which there are 25 thousand licensed patent agents, and more than 3 thousands of intellectual property rights personnel in Institutions of higher learning and scientific research, and so on. The total number of intellectual property practitioners in China is over 1 million. Providing effective scientific and technological services for patent inventions and advanced technology has always been the difficulty and short board for the development of Chinese technology. It is a highly 
valued and inefficient work of government and enterprises, and it should be one of the important points of the development of higher education. In the face of the huge development space for the demand of technology services and intellectual property talents, higher vocational colleges are faced with unprecedented opportunities. They should be active, create technology services and provide all kinds of supporting services for basic research, pilot and technical practice, including the evaluation of intellectual property analysis, operation and implementation, evaluation of transactions, and insurance. Safeguarding rights and interests, investing and financing, statistical investigation, information service and business incubation, promoting transformation and transfer of scientific and technological achievements.

\section{Conclusion}

"The transformation and application of Higher Vocational Education in original innovation, its solidarity, cooperation and diffusion and innovation in integrated innovation have their own advantages". The concept of dislocation development tells us that higher vocational education can not deny the mission of sci-tech innovation: in the specification of talent training, it is necessary to change from the operating skill talents to the innovative technology applied talents; in the direction of running a school, the important technology of technology industrialization should be actively invested with the concept of open development and synergistic innovation. In the new field, in sci-tech innovation, we should pay attention to the research and development of the applied technology, strengthen the integration innovation and application innovation around the industry and the market, and transform the core technology into the real economic benefit and the productive forces. Stimulating the innovative momentum of higher vocational education is the right choice to boost the national industry from the low level to the high level of the global value chain.

\section{Acknowledgements}

Project of the humanities and Social Sciences planning fund of the Ministry of education(China)" The Innovative Research on Mechanism of Open Education in Higher Vocational Colleges Under the New Normal" (No.: 16YJA880044)

\section{References}

[1] Joseph Alois Schumpeter. The theory of economic development [M].Cambridge: Harvard University Press, 1912.

[2] Peng Shuang, The structure, formation and operation of technological innovation chain, Technological progress and countermeasures, 9 (2012) 4-7.

[3] Lewis B. Lance Kam. Knowledge industrialization - ties between American and Japanese universities and industries, Beijing, Xinhua press, 2003:1.

[4] Zhang Zhihe, Zhao Gang, Xie Zhongquan, the frontier and measurement framework of innovation: a review of the Oslo Handbook, China soft science, 3 (2007):153-156.

[5] Bai Ling, Deng Wei, Why is technology innovation equally important in the middle and low technology industries? Social science front, 6(2008): 80-85.

[6] Wang ZhongTuo. "Soft innovation", Science and technology guide, 30(2012): 3.

[7] Gerd Bender, F Garibaldo, M Hancock, K Heanue, D Jacobson, Staffan Laestadius, T E Pedersen, K Schmierl. Peculiarities and Relevance of Non-Research-Intensive Industries in the Knowledge-Based Economy, Final Report of the PILOT[R].2006.

[8] See UPC705[OL],http://www.uspto.gov/web/offices/ac/ido/oeip/taf/def/705.thm. 
[9] T·Homer-Dison., The Ingenuity Gap: Can We solve the Problem of the Future?[M].Toronto ,Alfred A. Knopf, 2000:14.

[10] Information on http://www.sipo.gov.cn/zlssbgs/zlyj/201701/t20170120_1308051.html, 2017-01-20

[11] Yao Qifu. Research on the innovation of school running mode of higher vocational education, Hangzhou, Zhejiang University press, 2009:75-76, 99. 